\title{
ANALISIS PENYEBAB PENGANGGURAN LULUSAN SEKOLAH KEJURUAN DI JAWA BARAT DAN GARUT
}

\author{
Aditya Aprilliofany \\ Mahasiswa Magister Ekonomi Terapan, Sekolah Pascasarjana, Universitas Padjadjaran, \\ adityaaprilliofany@gmail.com
}

Diterima: Desember 2019; Direvisi: Februari 2020; Disetujui: April 2020

\begin{abstract}
Every business owner, that is large companies to small entrepreneurs, must have certain criteria in recruiting workers. In Indonesia, vocational schools are one solution for individuals to be able to get a job after graduating from their education. The fact is that vocational schools in Indonesia oppose the first placement with the open unemployment rate (TPT) compared to other levels of education. Not only in Indonesia, alumnus of vocational schools also have the largest TPT in West Java Province and Garut Regency. This research was conducted to find out what factors supported the collection of information on vocational schools in West Java Province and Garut Regency. The research uses two kinds of analysis, namely descriptive and quantitative analysis. The quantitative analysis used is binary logistic regression analysis using Stata software. The dependent variable of the study is the status of the work collected by the vocational school, that is, the purchase or work. The result are several factors caused unemployment of vocational graduated student, which are age, gender, status in the household, marital status, regional classification, and field classification.
\end{abstract}

Keywords: unemployment, binary logistic regression, vocational school.

Abstraksi. Setiap pemilik lapangan usaha, baik itu dari perusahaan besar sampai pengusaha kecil, pasti memiliki kriteria tertentu dalam merekrut tenaga kerjanya. Di Indonesia sekolah kejuruan merupakan salah satu solusi bagi individu untuk bisa cepat mendapatkan pekerjaan setelah lulus dari pendidikannya. Faktanya sekolah kejuruan di Indonesia justru menempati urutan pertama dengan tingkat pengangguran terbuka (TPT) dibandingkan dengan jenjang pendidikan lain. Tidak hanya di Indonesia saja, lulusan sekolah kejuruan juga memiliki TPT terbesar di Provinsi Jawa Barat dan Kabupaten Garut. Penelitian ini dilakukan bertujuan untuk mengetahui faktor apa saja yang berpengaruh terhadap pengangguran lulusan sekolah kejuruan di Provinsi Jawa Barat dan Kabupaten Garut. Adapun penelitian ini menggunakan dua macam analisis, yaitu analisis deskriptif dan kuantitatif, analisis kuantitatif yang digunakan disini adalah analisis regresi logistik biner dengan bantuan software Stata. Variabel dependen penelitian adalah status pekerjaan lulusan sekolah kejuruan, yaitu pengangguran atau bekerja. Hasil dari penelitian ini diperoleh beberapa faktor penyebab pengangguran lulusan sekolah kejuruan, yaitu umur, jenis kelamin, status dalam rumah tangga, status perkawinan, klasifikasi wilayah, dan klasifikasi jurusan.

Kata kunci: tidak bekerja, sekolah vokasi.

\section{PENDAHULUAN}

Mendapatkan pekerjaan adalah tujuan utama setiap angkatan kerja untuk memenuhi kebutuhan hidupnya. Setiap angkatan kerja yang ada pasti sudah mempersiapkan keahlian tertentu yang dapat digunakan untuk masuk di dunia kerja. Keahlian yang didapat tersebut bisa berupa pendidikan ataupun dari pelatihan. 
Banyak masyarakat di Indonesia yang menempuh pendidikan sampai jenjang perguruan tinggi hanya untuk mendapatkan pekerjaan yang layak. Namun bagi sebagian orang pendidikan sampai jenjang perguruan tinggi sulit untuk diperoleh, banyak faktor yang menyebabkan hal itu, diantaranya: keadaan ekonomi keluarga yang tidak memungkinkan untuk lanjut ke jenjang perguruan tinggi, atau stigma sebagian orang yang menganggap bahwa sekolah sampai jenjang perguruan tinggi pun tidak menjamin akan mendapatkan pekerjaan yang layak dan tepat untuk kehidupan ekonominya.

Demi mengakomodir masyarakat yang kurang mampu atau tidak berminat melanjutkan ke jenjang perguruan yang lebih tinggi, maka pemerintah Indonesia mendirikan berbagai macam sekolah khusus di berbagai macam jenjang pendidikan. Untuk di tingkat sekolah menengah atas, maka pemerintah membentuk sekolah kejuruan (SMK/MAK). Sedangkan untuk di jenjang perguruan tinggi, pemerintah membentuk sekolah kedinasan dimana setiap lulusannya akan langsung menjadi Aparatur Sipil Negara, seperti: IPDN, STAN, STIS, AMG, dll.

Sekolah kejuruan (SMK/MAK) adalah sekolah khusus yang didirikan oleh pemerintah, dimana nanti setiap lulusannya dipersiapkan untuk bisa terjun langsung ke dunia kerja. Para lulusan sekolah kejuruan ini dibekali dengan keahlian khusus tertentu agar menjadi daya Tarik tersendiri para pemilik lapangan pekerjaan untuk merekrut mereka. Hal ini sesuai dengan isi UndangUndang Sistem Pendidikan Nasional No. 20 Tahun 2003 Pasal 3 tentang tujuan pendidikan nasional dan penjelasan Pasal 15 yang menyebutkan bahwa pendidikan kejuruan merupakan pendidikan menengah yang khusus mempersiapkan peserta didiknya untuk siap bekerja di bidang tertentu.

Namun faktanya, menurut data Badan Pusat Statistik (BPS lulusan sekolah kejuruan memiliki angka tingkat pengangguran terbuka (TPT) terbesar terhadap angkatan kerjanya dibandingkan dengan lulusan sekolah pendidikan lain baik itu SD, SMP, sampai dengan Universitas dari bulan Agustus 2014 sampai dengan bulan Agustus 2018.

Provinsi Jawa Barat adalah salah satu Provinsi dengan nilai TPT terbesar jika dibandingkan dengan provinsi lain yang ada di Pulau Jawa, angka TPT Provinsi Jawa Barat hanya kalah dari Provinsi Banten saja. Hal ini wajar, mengingat Provinsi Banten adalah provinsi yang lebih muda dari segi usia dan juga merupakan pecahan dari Provinsi Jawa Barat. Tingginya angka TPT di Provinsi Jawa Barat apabila dilihat berdasarkan pendidikan tertinggi yang ditamatkan, maka lulusan sekolah tingkat menengah atas (SMA/SMK) memiliki TPT terbesar dibandingkan dengan lulusan jenjang pendidikan lain dari tingkat SD sampai Universitas, hal ini bisa dilihat di publikasi yang dikeluarkan oleh BPS Provinsi Jawa Barat yang berjudul Keadaan Angkatan Kerja Provinsi Jawa Barat, mulai dari Februari 2015 sampai dengan Agustus 2018.

Untuk mengatasi besarnya TPT lulusan sekolah kejuruan ini banyak upaya yang dilakukan, salah satunya dilakukan oleh salah satu SMK di Kabupaten Garut, SMK tersebut melakukan job matching dengan cara mengundang perusahaan-perusahaan baik local atau wilayah jabodetabek untuk mengurangi angka TPT ini.

Konsep dan definisi yang digunakan sama dengan yang digunakan oleh Badan Pusat Statistik (BPS). BPS mendefinisikan 
tenaga kerja mengacu pada The Labor Force Concept dari International Labor Organization (ILO). Menurut BPS penduduk dibagi menjadi dua, yaitu usia kerja dan bukan usia kerja. Usia kerja dibagi lagi mejadi dua, yaitu angkatan kerja atau bukan angkatan kerja. Angkatan kerja dibagi menjadi dua, yaitu bekerja atau menganggur, sedangkan yang termasuk bukan angkatan kerja adalah penduduk yang sekolah atau mengurus rumah tangga.

Menurut BPS penduduk yang masuk usia kerja adalah mereka yang berusia 15 tahun atau lebih. Sedangkan bekerja adalah kegiatan ekonomi yang dilakukan oleh seseorang dengan maksud memperoleh atau membantu dalam memperoleh pendapatan atau keuntungan, paling sedikit selama satu jam tidak terputus dalam seminggu terakhir, sedangkan pengangguran yang dipakai oleh BPS adalah pengangguran terbuka, yaitu seseorang yang tak pekerjaan dan mencari pekerjaan, mempersiapkan usaha, tidak mencari pekerjaan karena merasa putus asa, dan belum memulai pekerjaan.

Jenis kelamin, umur, status kawin, pendidikan, klasifikasi wilayah merupakan faktor yang diteliti oleh Shita dan Dereje (2018) untuk mengetahui penyebab pengangguran usia muda di zona Gojjam Timur wilayah Amhara. Sama dengan penelitian yang dilakukan oleh Pratiwi dan Zain (2014), bahwa untuk terdapat lima faktor utama penyebab pengangguran terbuka di Sulawesi Utara, yaitu jenis kelamin, pendidikan, umur, status dalam rumah tangga, dan status perkawinan. Penyebab pengangguran usia muda di Negara Tanzania ada beberapa faktor, diantaranya: lokasi tempat tinggal, status perkawinan, dan pendidikan (Msigwa dan Kipesha, 2013). Beberapa variabel diatas merupakan penelitian terdahulu yang dilakukan di negara berkembang yang ada di Benua Afrika dan beberapa daerah di
Indonesia. Mengingat Provinsi Jawa Barat dan Kabupaten Garut terletak di kawasan Industri dan termasuk di dalam Negara Indonesia yang termasuk sebagai negara berkembang, maka penelitian ini dirasa perlu dilakukan agar dapat lebih jelas mengukur pengangguran lulusan sekolah kejuruan di kawasan industri.

Penelitian ini bertujuan untuk menganalisis bagaimana pengaruh karakteristik individu lulusan sekolah kejuruan terhadap pengangguran lulusan sekolah kejuruan di Provinsi Jawa Barat pada bulan Agustus 2018.

\section{METODOLOGI}

\section{Sumber Data dan Definisi Operasional Variabel}

Penelitian ini bertujuan untuk menganalisis determinan pengangguran lulusan sekolah kejuruan di Provinsi Jawa Barat dan nantinya dibandingkan dengan Kabupaten Garut. Variabel-variabel yang ada berasal dari penelitian-penelitian terdahulu baik di dalam ataupun luar negeri. Data yang digunakan dalam penelitian ini adalah data sekunder dengan sumber datanya adalah raw data dari Survei Angkatan Kerja Nasional (Sakernas) bulan Agustus tahun 2018 yang dilakukan oleh Badan Pusat Statistik (BPS) di Provinsi Jawa Barat. Sampel yang digunakan dalam penelitian ini adalah individu yang termasuk sebagai lulusan sekolah kejuruan (SMK/MAK) dan menjadi bagian angkatan kerja.

Adapun variabel penelitian yang digunakan dalam penelitian ini diantaranya: Variabel dependen adalah status pekerjaan lulusan sekolah kejuruan. Sedangkan untuk variabel independennya adalah umur, jenis kelamin, status dalam rumah tangga, status perkawinan, klasifikasi wilayah, dan klasifikasi jurusan. Lebih jelasnya bisa dilihat pada definisi variabel di bawah ini: 
Tabel 1.

Definisi Variabel Dependen

\begin{tabular}{lclll}
\hline \multicolumn{1}{c}{ Klasifikasi } & $\begin{array}{c}\text { Variabel } \\
\text { Dummy }\end{array}$ & \multicolumn{2}{c}{ Keterangan } \\
\hline Pengangguran & 1 & $\begin{array}{l}\text { Jika Lulusan } \\
\text { menganggur }\end{array}$ & Sekolah & Kejuruan \\
Lainnya & 0 & $\begin{array}{l}\text { Jika Lulusan Sekolah } \\
\text { menganggur (Bekerja) }\end{array}$ & Kejuruan tidak \\
\hline
\end{tabular}

Tabel 2.

Definisi Variabel Independen

\begin{tabular}{|c|c|c|c|c|}
\hline No & Variabel & Kode & Definisi Operasional & Kategori \\
\hline 1 & Umur & $A G E$ & $\begin{array}{l}\text { Umur lulusan sekolah } \\
\text { kejuruan }\end{array}$ & Kontinyu \\
\hline 2 & Jenis Kelamin & FEMALE & $\begin{array}{l}\text { Jenis Kelamin lulusan } \\
\text { sekolah kejuruan }\end{array}$ & $\begin{array}{l}1=\text { perempuan } \\
0=\text { laki-laki }\end{array}$ \\
\hline 3 & $\begin{array}{l}\text { Status dalam } \\
\text { rumah tangga }\end{array}$ & $H M$ & $\begin{array}{l}\text { Status lulusan } \\
\text { kejuruan dalam rumah } \\
\text { tangga }\end{array}$ & $\begin{array}{l}1=\text { bukan kepala } \\
\text { rumah tangga } \\
0=\text { kepala rumah } \\
\text { tangga }\end{array}$ \\
\hline 4 & $\begin{array}{l}\text { Status } \\
\text { Perkwainan }\end{array}$ & SINGLE & $\begin{array}{l}\text { Status Perkawinan lulusan } \\
\text { sekolah kejuruan }\end{array}$ & $\begin{array}{l}1=\text { belum kawin } \\
0=\text { kawin }\end{array}$ \\
\hline 5 & $\begin{array}{l}\text { Klasifikasi } \\
\text { Wilayah }\end{array}$ & URBAN & $\begin{array}{l}\text { Lokasi tempat tinggal } \\
\text { lulusan sekolah kejuruan }\end{array}$ & $\begin{array}{l}1=\text { kota } \\
0=\text { desa }\end{array}$ \\
\hline 6 & $\begin{array}{l}\text { Klasifikasi } \\
\text { Jurusan }\end{array}$ & TEKNIS & $\begin{array}{l}\text { Jurusan yang diambil } \\
\text { lulusan sekolah kejuruan } \\
\text { saat masih mengenyam } \\
\text { pendidikan }\end{array}$ & $\begin{array}{l}1=\text { teknis } \\
0=\text { non teknis }\end{array}$ \\
\hline
\end{tabular}

\section{Metode Analisis}

Metode yang digunakan dalam penelitian ini adalah analisis deskriptif dan kuantitatif. Analisis deskriptif digunakan untuk melihat bagaimana gambaran lulusan sekolah kejuruan di Provinsi Jawa Barat dan Kabupaten Garut, sedangkan analisis kuantitatif digunakan untuk melihat hubungan dan pengaruh determinan yang ada terhadap pengangguran di Provinsi Jawa Barat dan Kabupaten Garut. Analisis kuantitatif yang digunakan dalam penelitian ini adalah analisis regresi logistik biner dengan bantuan software Stata.

\section{a) Model Regresi Logistik}

Model regresi logistik biner digunakan jika variabel dependennya berupa data kategori yang memiliki dua pilihan, rentang pilihan tersebut berada pada rentang 0 sampai dengan 1 , dimana 0 adalah peluang gagal dan 1 adalah peluang berhasil. Sedangkan untuk variabel bebasnya bisa berskala kategorik ataupun kontinyu (Hosmer and Lemeshow, 1989).

Model umum regresi logistic dengan $\mathrm{p}$ variabel penjelas sebagai berikut: 


$$
P_{1}=\frac{\exp \left(\beta_{0}+\beta_{1} X_{1}+\beta_{2} X_{2}+\cdots+\beta_{p} X_{p}\right)}{1+\exp \left(\beta_{0}+\beta_{1} X_{1}+\beta_{2} X_{2}+\cdots+\beta_{p} X_{p}\right)}
$$

Dimana:

$P_{1}=$ Peluang kejadian saat $\mathrm{Y}=1$,

$\beta_{p}=$ Nilai Parameter ke- $\mathrm{j} ; \mathrm{j}=0,1,2, \ldots, \mathrm{p}$

Formula diatas adalah model non linier, sehingga perlu dilakukan transformasi agar menjadi model linier, hal ini disebut dengan transformasi logit, hasilnya akan berubah menjadi seperti berikut:

$$
\begin{aligned}
& L_{1}=\ln \left(\frac{P_{1}}{1-P_{1}}\right)=\beta_{0}+\beta_{1} X_{1}+ \\
& \beta_{2} X_{2}+\cdots+\beta_{p} X_{p}
\end{aligned}
$$

\section{b) Uji Kelayakan Model (Goodness of Fit)}

Menurut Hosmer dan Lemeshow (2000), suatu model dapat dikatakan memenuhi goodness of fit jika terdapat kesesuaian antara data yang diamati dengan data yang dimasukkan ke dalam model. Dalam pengolahan data sendiri model dapat dikatakan cocok apabila nilai p-value nya lebih besar dari tingkat signifikansinya.

\section{c) Uji Likelihood Ratio}

Uji likelihhod ratio digunakan untuk mengetahui pengaruh variabel penjelas terhadap variabel respon secara bersamasama (overall) di dalam model regresi logistic. Hipotesis dalam uji likelihood sebagai berikut:

$H_{0} \quad: \beta_{0}=\beta_{1}=\beta_{2}={ } . . .=\beta_{k}=0$

$H_{1}: \beta_{j} \neq 0, \mathrm{j}=1,2, \ldots, \mathrm{k}$,

artinya minimal ada satu koefisien $\beta_{j}$ tidak sama dengan nol atau minimal ada satu variabel bebas yang berpengaruh terhadap variabel dependen.

Uji statistik ini mengikuti distribusi chisquare dengan derajat bebas $\mathrm{k}$. keputusan tolak $H_{0}$ jika nilai $p$-value $<\alpha$ (Gujarati, 2004).

\section{d) Uji Parsial}

Pengujian parameter secara parsial dilakukan dengan menggunakan statistik uji $\mathrm{z}$ atau statistik uji Wald. Tujuan dilakukan uji parsial ini adalah untuk mengetahui pengaruh masing-masing variabel penjelas secara individual (parsial) terhadap variabel dependen. Statistik uji Wald ini dituliskan dalam bentuk sebagai berikut:

$$
W_{j}=\left(\frac{\widehat{\beta}_{j}}{s e\left(\widehat{\beta}_{j}\right)}\right)^{2}, \mathrm{j}=1,2, \ldots, \mathrm{p}
$$

\section{Dimana:}

$W_{j}=$ Wald test pada variabel bebas ke- $\mathrm{j}$

$\beta_{j} \quad=$ Estimasi parameter pada variabel bebas ke- $\mathrm{j}$

$\operatorname{se} \beta_{j}=$ standar error dari parameter pada variabel bebas ke- $\mathrm{j}$

Statistik Wald mengikuti distribusi chisquare dengan derajat bebas $=1$. Uji Parsial ini memiliki Keputusan Tolak $H_{0}$ jika nilai $p$-value $<\alpha$ atau Wald $>X_{\alpha: 1}^{2}$ (Agresti, 2000).

\section{e) Marginal Effect}

Hasil koefisien variabel bebas yang didapat pada logit tidak dapat diinterpretasikan langsung layaknya model regresi linear. Model logit tersebut harus ditransformasi ke dalam nilai marginal effect agar dapat diperoleh besarnya perubahan probabilita $(\mathrm{Pi})$ yang terjadi oleh perubahan setiap $x$. Secara matematis dapat dijabarkan seperti berikut:

$$
\frac{\partial F\left(x^{\prime} \beta\right)}{\partial x}=\frac{e^{z}}{\left(1+e^{z}\right)^{z}} \beta_{i}
$$


Keterangan:

$\partial F\left(x^{\prime} \beta\right)=\partial y=\partial p \quad$ : perubahan nilai $\mathrm{y} /$ perubahan peluang

$\partial x \quad$ : perubahan nilai $\mathrm{x}$

$z \quad: \beta_{0}+\beta_{i} X_{i}$

$\beta_{i} \quad:$ koefisien variabel

\section{Model Penelitian}

Model dalam penelitian ini merujuk kepada model penelitian penelitianpenelitian terdahulu dengan beberapa modifikasi dan penyesuaian kondisi Negara dan wilayah. Persamaan tersebut dirumuskan untuk menjawab tujuan penelitian ini, yaitu untuk mengetahui hubungan antara determinan yang ada dengan pengangguran lulusan sekolah kejuruan di Provinsi Jawa Barat dan Kabupaten Garut.

Model penelitian yang digunakan adalah sebagai berikut:

$$
\begin{aligned}
U N E M_{1}=\ln ( & \left.\frac{P_{1}}{1-P_{1}}\right) \\
& =\beta_{0}+\beta_{1} A G E_{i}+\beta_{2} \text { FEMALE }_{i} \\
& +\beta_{3} H M_{i}+\beta_{4} \text { SINGLE }_{i} \\
& +\beta_{5} \text { URBAN }_{i}+\beta_{6} \text { TEKNIS }_{i} \\
& +\varepsilon_{i}
\end{aligned}
$$

Dimana UNEM adalah status pekerjaan lulusan sekolah kejuruan, dengan $P_{1}$ adalah peluang lulusan sekolah kejuruan menjadi pengangguran dan $1-P_{1}$ adalah peluang lulusan sekolah kejuruan bekerja. Lebih jelasnya bisa dilihat pada definisi operasional sebelumnya.

\section{HASIL DAN PEMBAHASAN}

\section{Gambaran Umum}

Dari Gambar 1 bisa dilihat bahwa di Provinsi Jawa Barat dan Kabupaten Garut lulusan sekolah kejuruan lebih banyak yang bekerja daripada menganggur. Artinya bahwa untuk Provinsi Jawa Barat lulusan sekolah kejuruan yang menganggur sebanyak 16 sampai 17 orang dari 100 orang lulusan sekolah kejuruan yang ada, sedangkan di Kabupaten Garut dari 100 orang lulusan sekolah kejuruan terdapat 18 sampai 19 orang yang menganggur.

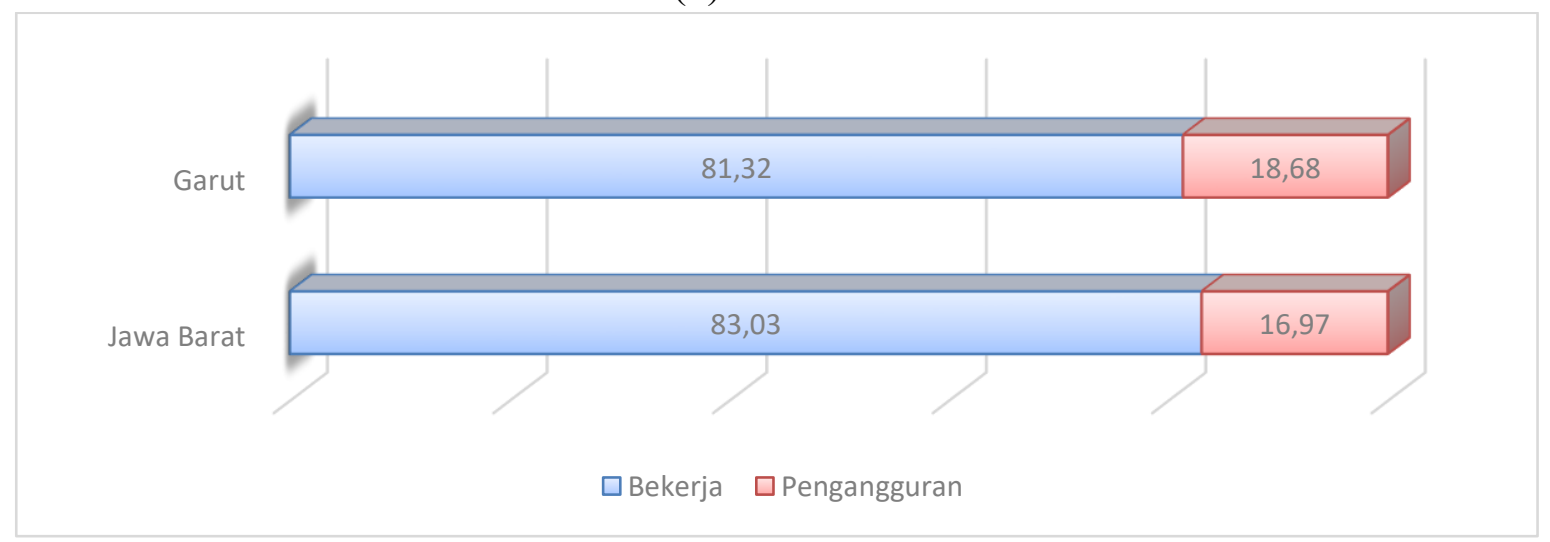

Gambar 1.

Perbandingan Persentase Status Pekerjaan Lulusan Sekolah Kejuruan di Provinsi Jawa Barat dan Kabupaten Garut, Agustus 2018 (Sumber: Sakernas Agustus 2018 Jabar (diolah) 
Tabel 3.

Gambaran Umum Variabel Independen yang Memiliki Dummy/ Kategori, Agustus 2018

\begin{tabular}{clcc}
\hline \multicolumn{1}{c}{ Variabel } & \multicolumn{1}{c}{ Dummy/Kategori } & Jawa Barat & \multicolumn{1}{c}{ Garut } \\
\hline \multicolumn{1}{c}{$(\mathbf{1})$} & \multicolumn{1}{c}{$(\mathbf{2})$} & $(\mathbf{3})$ & $(\mathbf{4})$ \\
\hline \multirow{2}{*}{ Jenis Kelamin } & Laki-laki (0) & $71.9 \%$ & $72.6 \%$ \\
& Perempuan (1) & $28.1 \%$ & $27.4 \%$ \\
\hline \multirow{2}{*}{$\begin{array}{c}\text { Status dalam Rumah } \\
\text { Tangga }\end{array}$} & Kepala Rumah Tangga (0) & $33.0 \%$ & $26.8 \%$ \\
& Bukan Kepala Rumah Tangga (1) & $67.0 \%$ & $73.2 \%$ \\
\hline \multirow{2}{*}{ Status Perkawinan } & Kawin/Cerai Hidup/Cerai Mati & & \\
& $(0)$ & $50.0 \%$ & $37.8 \%$ \\
& Belum Kawin (1) & & \\
\multirow{2}{*}{ Klasifikasi Wilayah } & Perdesaan (0) & $50.0 \%$ & $62.2 \%$ \\
\hline \multirow{2}{*}{ Klasifikasi Jurusan } & Perkotaan (1) & $11.6 \%$ & $32.3 \%$ \\
& Non Teknis (0) & $88.4 \%$ & $67.7 \%$ \\
\hline
\end{tabular}

Sumber: Sakernas Agustus 2018 Jabar (diolah)

Dari tabel 3 bisa kita lihat karakteristik lulusan sekolah kejuruan yang berstatus variabel independen yang ada di Jawa Barat belum kawin ternyata sama banyak dengan dan Garut. Lulusan sekolah kejuruan di lulusan sekolah kejuruan yang berstatus Provinsi Jawa Barat dan Kabupaten Garut kawin, cerai hidup, dan cerai mati di mayoritas adalah laki-laki, berstatus bukan Provinsi Jawa Barat. Sedangkan di kepala rumah tangga, tinggal di daerah Kabupaten Garut lulusan sekolah kejuruan perkotaan, dan memiliki kualifikasi jurusan banyak yang berstatus belum kawin. teknis. Hal yang sedikit berbeda adalah

Tabel 4.

Persentase Pengangguran Lulusan Sekolah Kejuruan di Jawa Barat dan Kabupaten Garut, Agustus 2018

\begin{tabular}{llrr}
\hline \multicolumn{1}{c}{ Variabel } & \multicolumn{1}{c}{ Dummy/Kategori } & Jawa Barat & \multicolumn{1}{c}{ Garut } \\
\hline \multirow{2}{*}{ Jenis Kelamin } & Laki-laki (0) & $67.4 \%$ & $91.9 \%$ \\
& Perempuan (1) & $32.6 \%$ & $8.1 \%$ \\
\hline \multirow{2}{*}{$\begin{array}{l}\text { Status dalam Rumah } \\
\text { Tangga }\end{array}$} & Kepala Rumah Tangga (0) & $4.5 \%$ & $5.2 \%$ \\
& Bukan Kepala Rumah Tangga (1) & $95.5 \%$ & $94.8 \%$ \\
\hline \multirow{2}{*}{ Status Perkawinan } & Kawin/Cerai Hidup/Cerai Mati (0) & $9.7 \%$ & $5.2 \%$ \\
& Belum Kawin (1) & $90.3 \%$ & $94.8 \%$ \\
\hline \multirow{2}{*}{ Klasifikasi Wilayah } & Perdesaan (0) & $15.7 \%$ & $36.1 \%$ \\
& Perkotaan (1) & $84.3 \%$ & $63.9 \%$ \\
\hline \multirow{2}{*}{ Klasifikasi Jurusan } & Non Teknis (0) & $27.4 \%$ & $30.1 \%$ \\
& Teknis (1) & $72.6 \%$ & $69.9 \%$ \\
\hline
\end{tabular}

Sumber: Sakernas Agustus 2018 Jabar (diolah) 
Dari tabel 4. diatas bisa dilihat bahwa lulusan sekolah kejuruan di Jawa Barat dan Garut yang menjadi pengangguran banyak yang berjenis kelamin laki-laki, berstatus bukan sebagai KRT, berstatus belum kawin, tinggal di daerah perkotaan dan memiliki kualifikasi jurusan teknis.

\section{Pengaruh Variabel Bebas Terhadap Pengangguran Lulusan Sekolah Kejuruan di Provinsi Jawa Barat dan Kabupaten Garut}

a. Uji Kelayakan Model (Goodness of Fit)

Uji kelayakan model (goodness of fit) digunakan untuk mengetahui akurasi prediksi model tersebut tepat digunakan atau tidak, nilai goodness of fit ini dalam bentuk persen. Semakin besar nilai persentasenya maka model tersebut akan semakin baik. Dari hasil pengujian dalam penelitian ini didapatkan hasil sebesar 83,03 persen untuk Provinsi Jawa Barat dan 82,22 persen untuk Kabupaten Garut. Hasil ini bisa dikatakan sudah baik dimana variabel bebas yang ada dapat menjelaskan variabel bebasnya yaitu pengangguran lulusan sekolah kejuruan di Provinsi Jawa Barat dan Kabupaten Garut. Hal ini dapat dilihat pada tabel 5 pada baris Correctly Classified.

Tabel 5.

Persentase Pengangguran Lulusan Sekolah Kejuruan di Jawa Barat dan Kabupaten Garut, Agustus 2018

\begin{tabular}{|c|c|c|c|c|c|c|c|}
\hline \multirow[b]{2}{*}{ No } & \multirow[b]{2}{*}{ Variabel } & \multicolumn{3}{|c|}{ Jawa Barat } & \multicolumn{3}{|c|}{ Garut } \\
\hline & & Koef & Prob & $\begin{array}{c}\text { Marginal } \\
\text { Effect }\end{array}$ & Koef & Prob & $\begin{array}{c}\text { Marginal } \\
\text { Effect }\end{array}$ \\
\hline 1 & AGE & -0.0882 & 0.000 & -0.0105 & -0.1700 & 0.000 & -0.0193 \\
\hline 2 & FEMALE & -0.0486 & 0.000 & -0.0058 & -3.6143 & 0.000 & -0.4104 \\
\hline 3 & $\mathrm{HM}$ & 0.7739 & 0.000 & 0.0917 & -2.1486 & 0.000 & -0.2440 \\
\hline 4 & SINGLE & 1.2245 & 0.000 & 0.1451 & 2.0063 & 0.000 & 0.2279 \\
\hline 5 & URBAN & -0.2346 & 0.000 & -0.0278 & -0.2470 & 0.000 & -0.0280 \\
\hline 6 & TEKNIS & 0.2014 & 0.000 & 0.0239 & -2.0351 & 0.000 & -0.2311 \\
\hline 7 & $\mathrm{C}$ & -0.7678 & 0.000 & & 5.2262 & & \\
\hline 8 & Pseudo R2: & \multicolumn{3}{|c|}{0.1978} & \multicolumn{3}{|c|}{0.2706} \\
\hline 9 & $\begin{array}{l}\text { Prob (LR } \\
\text { Stat): }\end{array}$ & \multicolumn{3}{|c|}{0.0000} & \multicolumn{3}{|c|}{0.0000} \\
\hline 10 & $\begin{array}{l}\text { Correctly } \\
\text { Classified: }\end{array}$ & \multicolumn{3}{|c|}{$83.03 \%$} & \multicolumn{3}{|c|}{$82.22 \%$} \\
\hline
\end{tabular}

Sumber: Sakernas Agustus 2018 Jabar (diolah)

\section{b. Hasil Uji Likelihood Ratio}

Uji likelihood ratio digunakan untuk mengetahui apakah model tersebut signifikan secara simultan artinya uji ini digunakan untuk mengetahui apakah variabel bebas yang ada memiliki pengaruh yang nyata terhadap variabel dependen/terikatnya. Uji likelihood ratio ini biasa digunakan dalam analisis regresi logistik. Analisis regresi logistik apabila menggunakan software stata, maka uji likelihood ratio ini bisa dilihat pada nilai probabilitas LR Stat. Dalam penelitian ini baik di Provinsi Jawa Barat atau Kabupaten 
Garut diperoleh bahwa nilai LR Stat sebesar 0,0000 karena nilai LR Stat ini lebih kecil dari $\alpha$ yang sebesar 0,05. Hal ini menunjukkan bahwa ada hubungan antara variabel bebas dengan variabel dependen secara signifikan. Artinya semua variabel bebas yang ada dalam model secara bersama-sama secara statistik dapat mempengaruhi variabel dependen/terikat, sehingga model dianggap baik dan tepat untuk memprediksi peluang lulusan sekolah kejuruan menjadi pengangguran serta dapat digunakan untuk analisis berikutnya.

\section{c. Hasil Uji Signifikansi Parsial (Uji z)}

Pengujian ini digunakan untuk mengetahui signifikansi masing-masing parameter yang ada dalam model regresi logistik, sehingga bisa mengetahui setiap variabel bebas yang ada dalam model memiliki pengaruh signifikan secara statistik terhadap variabel terikatnya. Karena penelitian ini menggunakan alat analisis stata, maka tingkat signifikansinya bisa dilihat pada kolom $\mathrm{P}>|\mathrm{z}|$ atau lebih jelasnya bisa dilihat pada tabel 3 di kolom (4) dan (7). Untuk Provinsi Jawa Barat dan Kabupaten Garut dari enam variabel yang ada, seluruhnya signifikan karena setiap variabel masing-masing memiliki probabilitas 0,000 .

\section{d. Marginal Effect}

Marginal effect digunakan untuk menganalisis nilai ekonomi yang ada dalam penelitian ini. Adapun hasil dari penelitian ini sebagai berikut:

1) Umur

Nilai marginal effect variabel umur di Provinsi Jawa Barat dan Kabupaten Garut masing-masing sebesar -0,0105 dan -0,0193. Artinya setiap kenaikan 1 tahun umur, maka peluang lulusan sekolah kejuruan menjadi pengangguran di
Provinsi Jawa Barat akan berkurang sebesar 1,05 persen, sedangkan di Kabupaten Garut berkurang sebesar 1,93 persen.

2) Jenis Kelamin

Nilai marginal effect variabel jenis kelamin di Provinsi Jawa Barat dan Kabupaten Garut masing-masing sebesar -0,0058 dan -0,4104. Artinya peluang lulusan sekolah kejuruan yang berjenis kelamin perempuan untuk menjadi pengangguran turun sebesar 0,58 persen di Provinsi Jawa Barat dan turun sebesar 41,04 persen di Kabupaten Garut.

3) Status dalam Rumah Tangga

Nilai marginal effect variabel status dalam rumah tangga di Provinsi Jawa Barat dan Kabupaten Garut masing-masing sebesar 0,0917 dan 0,2440 . Artinya peluang lulusan sekolah kejuruan dengan status kepala rumah tangga untuk menjadi pengangguran turun sebesar 9,17 persen di Provinsi Jawa Barat, sedangkan untuk Kabupaten Garut lulusan sekolah kejuruan dengan status kepala rumah tangga justru memiliki peluang untuk menjadi pengangguran naik sebesar 24,40 persen.

4) Status Perkawinan

Nilai marginal effect variabel status perkawinan di Provinsi Jawa Barat dan Kabupaten Garut masingmasing sebesar 0,1451 dan 0,2279. Artinya peluang lulusan sekolah kejuruan yang berstatus kawin, cerai hidup, dan cerai mati untuk menjadi pengangguran turun sebesar 14,51 persen di Provinsi Jawa Barat dan turun sebesar 22,79 persen di Kabupaten Garut. 
5) Klasifikasi Wilayah

Nilai marginal effect variabel klasifikasi wilayah di Provinsi Jawa Barat dan Kabupaten Garut masingmasing sebesar $-0,0278$ dan $-0,0280$. Artinya peluang lulusan sekolah kejuruan yang tinggal di daerah perkotaan untuk menjadi pengangguran turun sebesar 2,78 persen di Provinsi Jawa Barat dan turun sebesar 2,80 persen di Kabupaten Garut.

6) Klasifikasi Jurusan

Nilai marginal effect variabel klasifikasi jurusan di Provinsi Jawa Barat dan Kabupaten Garut masingmasing sebesar 0,0239 dan -0,2331. Artinya peluang lulusan sekolah kejuruan dengan kualifikasi jurusan non teknis untuk menjadi pengangguran turun sebesar 2,39 persen di Provinsi Jawa Barat, sedangkan untuk Kabupaten Garut lulusan sekolah kejuruan dengan kualifikasi jurusan non teknis justru memiliki peluang untuk menjadi pengangguran naik sebesar 23,11 persen.

\section{SIMPULAN}

Kesimpulan dari penelitian ini adalah dari enam variabel bebas yang ada seluruhnya signifikan dan memiliki pengaruh terhadap pengangguran lulusan sekolah kejuruan di Provinsi Jawa Barat dan Kabupaten Garut. Di Provinsi Jawa Barat lulusan sekolah kejuruan yang memiliki peluang untuk menjadi pengangguran lebih besar adalah mereka yang berusia muda, berjenis kelamin lakilaki, berstatus bukan sebagai kepala rumah tangga, belum kawin, tinggal di daerah perdesaan dan memiliki kualifikasi jurusan teknis. Sedangkan untuk Kabupaten Garut, peluang lulusan sekolah kejuruan untuk menjadi pengangguran adalah mereka yang berusia muda, berjenis kelamin laki-laki, berstatus sebagai kepala rumah tangga, belum kawin, tinggal di daerah perdesaan, dan memiliki kualifikasi jurusan non teknis.

\section{DAFTAR PUSTAKA}

Agresti, A. (1990). Categorical Data Analysis.Florida: John Wiley \& Sons.

Ahmad, Rizwan dan Parvez Azim. (2010). Youth Population and The Labour Market of Pakistan: a Micro Level Study. Pakistan Economic and Social Review. Vol . 48. No. 2 (Winter 2010). pp 183-208.

Ashshidiq, M. H. dan Rani Nooraeni. (2019). Faktor-Faktor yang Memengaruhi Pemuda Menjadi Pengangguran di Provinsi Banten Tahun 2018. [Jurnal]. Jakarta: Politeknik Statistika STIS.

Badan Pusat Statistik. (2017). Pedoman Survei Angkatan Kerja Nasional 2017. Jakarta: BPS.

Badan Pusat Statistik (2017). Keadaan Angkatan Kerja di Indonesia Agustus 2017. Jakarta: BPS.

Badan Pusat Statistik (2018). Pedoman Survei Angkatan Kerja Nasional 2018. Jakarta: BPS. 
Badan Pusat Statistik (2018). Keadaan Angkatan Kerja di Indonesia Agustus 2018. Jakarta: BPS.

Badan Pusat Statistik Provinsi Jawa Barat. (2015). Keadaan Angkatan Kerja di Provinsi Jawa Barat Agustus 2015. Bandung: BPS Provinsi Jawa Barat.

Badan Pusat Statistik Provinsi Jawa Barat. (2016). Keadaan Angkatan Kerja di Provinsi Jawa Barat Agustus 2016. Bandung: BPS Provinsi Jawa Barat.

Badan Pusat Statistik Provinsi Jawa Barat. (2017). Keadaan Angkatan Kerja di Provinsi Jawa Barat Agustus 2017. Bandung: BPS Provinsi Jawa Barat.

Badan Pusat Statistik Provinsi Jawa Barat. (2018). Keadaan Angkatan Kerja di Provinsi Jawa Barat Agustus 2018. Bandung: BPS Provinsi Jawa Barat.

Becker, Gary S. (1985). Human Capital, Effort, and the Sexual Division of Labor. Journal of Labour Economics. 1985. Vol 3 no.1 pt.2.

Dagume, Mbullahei Albert dan Agyapong Gyekye (2016). Determinants of Youth Unemployment in South Africa: Evidence From The Vhembe District of Limpopo Province. Environmental Economics. Volume 7. Issue 4. 2016.

Hosmer, David W. and Stanley Lemeshow. (1989). Applied Logistic Regression (2_ed). New Jersey: John Wiley and Sons, Inc.

Hosmer, David W. and Stanley Lemeshow. (2000). Applied Logistic Regression. Canada: John Wiley and Sons.

Kurniawan dan Husin. (2013). Analisis Lama Mencari Kerja Bagi Tenaga Kerja Terdidik di Kabupaten Purworejo. Diponegoro Journal of Economics, Volume 2, Nomor 4, Tahun 2013. Fakultas Ekonomika dan Bisnis Universitas Diponegoro, Semarang.

Mariska, Asyiek, dan Husin. (2016). Faktor-Faktor yang Mempengaruhi Lama Mencari Kerja Tenaga Kerja Terdidik Pada Pemerintahan Kota Prabumulih. Jurnal IEconomic Vol. 2 No. 2 Desember 2016. Program Pasca Sarjana Universitas Sriwijaya, Palembang.

Msigwa, Robert dan Erasmus Fabian Kipesha. (2013). Determinants of Youth Unemployment in Developing Countries: Evidences from Tanzania. Journal of Economics and Sustainable Development. Vol.4. No.14. 2013. Pages 67-76.

Pasay, N. Haidy dan Ratna Indrayanti. (2012). Pengangguran, Lama Mencari Kerja, dan Reservation Wage Tenaga Kerja Terdidik. Jurnal Ekonomi dan Pembangunan Indonesia Vol. 12 No.2, Januari 2012. Lembaga Demografi FEUI, Depok.

Pratiwi, Febti Eka dan Ismaini Zain. (2014). Klasifikasi Pengangguran Terbuka Menggunakan CART (Classification and Regression Tree) di Provinsi Sulawesi Utara. Jurnal Sains dan Semi Pomits Vol. 3, No.1, (2014) 2337-3520 (2301928X Print).

Qayyum, Waqqas dan Rizwana Siddiqui. (2007). Causes of Youth Unemployment in Pakistan. The Pakistan Development Review. Vol. 46 No.4 Part II (Winter 2007) pp. 611-621.

Santoso, Rokhedi Priyo. (2012). Ekonomi Sumber Daya Manusia dan Ketenagakerjaan. Yogyakarta: UPP STIM YKPN. 
Shita, Aynalem dan Mulugeta Dereje. (2018). Determinants of Urban Youth Unemployment; Evidence From East Gojjam Zone of Amhara Region, Ethiopia. International Journal of Economic Development Volume 11,245-265.

Sipayung dan Waridin. (2013). Analisis Keputusan Wanita Menikah Untuk Bekerja (Studi Kasus Kota Surakarta Jawa Tengah). Diponegoro Journal of Economics, Volume 2, Nomor 4, Tahun 2013. Fakultas Ekonomika dan Bisnis Universitas Diponegoro, Semarang. 